\title{
500 penile prostheses implanted by a surgeon in Italy in the last $\mathbf{3 0}$ years
}

\author{
Diego Pozza ${ }^{1}$, Mariangela Pozza ${ }^{1}$, Marco Musy $^{1}$, Carlotta Pozza $^{2}$ \\ ${ }^{1}$ Studio di Andrologia e di Chirurgia Andrologica, Rome, Italy; \\ ${ }^{2}$ Department of Experimental Medicine, Sapienza University of Rome, Italy.
}

\begin{abstract}
Summary Objectives: The aim of our study was to report our experience with patients affected by Erectile Dysfunction (ED) and undergoing penile prosthetic implantation (PPI) in a single center by a single surgeon.

Material and Methods: We retrospectively evaluated the clinical outcome of 500 patients (mean age: 51.5 years, range: 20-86 years) affected by ED and referred to our private andrological center from January 1984 to December 2013 who underwent penile prosthesis implantation, including the reported level of patient satisfaction.

Results: 182 silicone, 180 malleable, 18 monocomponent hydraulic and 120 multicomponents hydraulic prostheses were implanted by the same experienced surgeon. All patients were hospitalized for the procedure. All patients were evaluated immediately, 1 month (496 patients) and, for the great majority, every year after implantation. One hundred twenty five patients were lost to follow-up. Twenty two patients underwent revision surgery for complications in the postoperative period. The most serious postoperative complications were mechanical problems (45 patients, 9.0\%) and infection (15 patients, 3\%). Forty two (8.4\%) prostheses were explanted. Overall, 80\% (400/500) of patients were able to have sexual intercourse and were fully satisfied with the results.

Conclusions: In our experience prosthetic surgery should be considered a good solution for men affected by ED and not responsive to other therapeutic solutions. Prosthetic surgery can be performed not only in large public hospitals but also in smaller private facilities.
\end{abstract}

KEY WORDS: Impotence; Erectile Dysfunction; Penile Disease; Penile Prosthesis; Impotence Treatment; Impotence Surgery; Prosthesis Complications; Prosthesis Infections.

Submitted 5 January 2015; Accepted 31 March 2015

\section{INTRODUCTION}

Over the last century, efforts to treat ED have led to the development and use of psychological treatment (early 1900s), hormonal therapies $(1960)(1,2)$, prosthetic surgery $(1971)(3,4)$, arteriovenous surgery $(1981)(5,6)$, vasoactive intracavernosal self-injection (1982) $(7,8)$, vacuum pumps (1986) (9), intraurethral PGEl-medicated urethral system for erections (MUSE) (1994) (10) and 5phosphodiesterases inhibitors (5PDHEi) (1997) (11).
In Italy, the use of MUSE and vacuum pumps never spread, and penile prosthesis implantation (PPI) did not develop as in other western countries.

Our private andrology center has been performing PPI, carried out by the same experienced surgeon (DP) since 1984. After 30 years of surgical activity we wanted to review our experience with 500 patients affected by ED and undergoing PPI. We report the different types of implanted prostheses, any complication (medical complications, hemorrhages, micturition problems, infections, mechanical failures during hospitalization and the postoperative period) and the level of personal and relational acceptance of this ED treatment.

\section{Materials AND Methods}

From January 1984 to December 2013, 35,675 patients (5-86 years old, mean age: 48.8) underwent an andrological visit at our andrology center due to routine uroandrological screening (1097 pts. 3.0\%), bladder and prostate diseases (4826 pts., 13.5\%), genital malformations (2120 pts., $5.9 \%$ ), infertility (12.555 pts., 35.2\%), urogenital infections (6400 pts., 17.9\%), ejaculatory (1645 pts., $4.6 \%)$ or erectile problems (8032 pts., 22.5\%) (Figure 1).

One specialist (DP) saw all the pts., collected their medical history, performed the clinical examination and organized the diagnostic protocol, at the end of which an individualized therapeutic measure was suggested.

A total of 8032 pts. (22.5\%, mean age 48 years, range 18 86 years) attended the center for problems concerning the penis and its function. Out of them 436 (6\%) did not return for successive consultations. In total 7564/8032 patients completed the diagnostic program, all undergoing blood and hormone assays, color duplex ultrasonography and intracavernous PGE1 test. Furthermore 383 patients underwent the Rigiscan nocturnal test and, up to 2008, 212 patients underwent dynamic cavernosometry and cavernosography. Other specific investigations were performed in particular cases.

In 1984, at the beginning of our experience, only psychological, hormonal and surgical (prostheses) solutions could be offered to patients with ED. In 1987 we started offering self-injections of vasoactive drugs $(7,8)$. Between 1988 and 1998 we performed 86 venous surgical procedures $(5,6)$. 
Figure 2.

Flow diagram of the study.

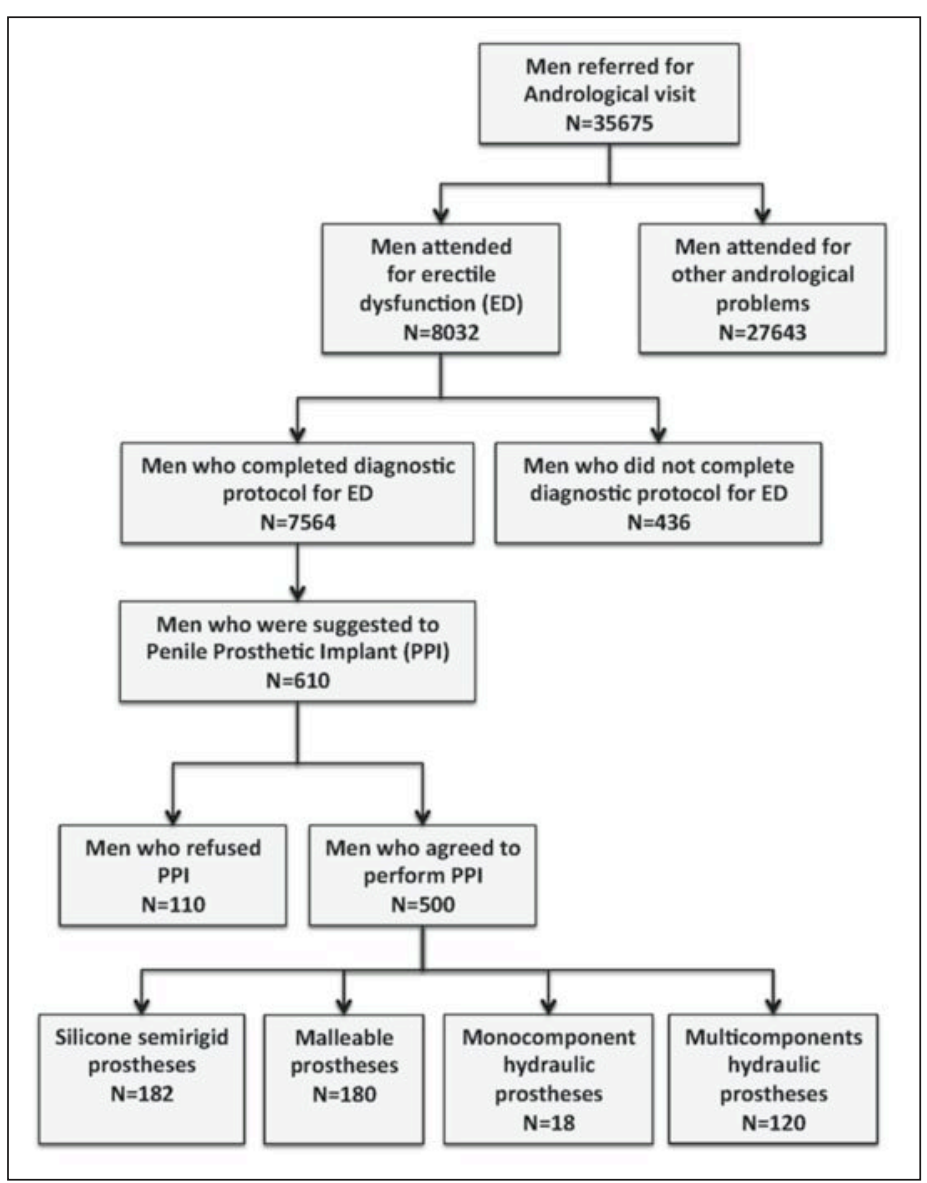

trative ability was suggested to 610 patients. 500 (81\%) patients agreed to the procedure. All patients in a stable relationship were asked to inform their partner about their choice. The conclusive diagnosis of these 500 patients was: arterial disease in 192 (38.4\%), venous disease in 137 (27.4\%), Peyronie's disease in 70 (14.0\%), diabetes mellitus in $60(12.0 \%)$ and previous pelvic surgery in 30 (6.0\%). 11 (2.2\%) patients with no specific organic disease opted for a prosthetic implant after psychotherapy (Table 1).

\section{Surgical procedure}

Until 2002, patients were admitted to the clinic the day before operation $(332 / 500,66 \%)$. In the last 10 years we have preferred, when possible, to hospitalize patients on the day of surgery $(168 / 500,34 \%)$. Patients stayed in the clinic for at least 24 hours. Hospitalization duration ranged between 1 and 7 days (mean 2.6).

In the last 13 years we have generally prescribed oral Ciprofloxacin from 3 days before surgery to 7 days post-surgery, Gentamicin sulfate $80 \mathrm{mg}$ intravenously from 1 day before surgery to 1 day postsurgery and Ceftriaxone $2 \mathrm{~g}$. intravenously just before surgery and $1 \mathrm{~g}$ for 7 days post-surgery.

Patients were recommended to clean their genitals with Iodopovidone fluid twice a day for the 3 days leading up to surgery (12). Since 2006, we have performed skin shaving as routinely done for other surgical procedures a few hours before surgery. Usual Iodopovidone cleansing in the operating table.

In 76 cases (mainly at the beginning of our experience) we used general anesthesia. Currently, most procedures are performed under spinal anes-

With the appearance of 5PDEis in 1997 (11), many of our patients were able to benefit from a simple new treatment. The vacuum system (9) and MUSE (10) were rarely suggested for the treatment of ED in our patients.

Patients who underwent PPI signed a detailed informed consent form and agreed to pay the related costs (private clinic, surgical and anesthesiologist fees, prosthesis, postoperative follow-up). These medical expenses are not covered by the Italian National Health Service. This aspect undoubtedly influenced the choice of many patients as to whether or not to opt for surgery and if so, what prosthesis to implant; many patients could not afford this option.

Any aspirin and anticoagulant treatments were stopped 10 days before surgery. In all diabetic patients, blood glucose levels were stabilized before surgery.

\section{RESULTS}

Of the 7564 pts with ED, 3010 (39.8\%) were diagnosed with arterial insufficiency, 1339 (17.7\%) with Peyronie's disease, 1135 (15.0\%) with venous insufficiency, 1029 (13.6\%) with diabetic neurovascular problems, 393 (5.2\%) with hormonal dysfunction, 340 (4.5\%) with post-surgical neurovascular problems, and 318 (4.2\%) with psycho-morphological complaints.

Implantation of a cavernous prosthesis to restore penethesia. In 68 cases of implants of semi-rigid malleable rods we used local anesthesia with deep sedation. A urethral catheter was inserted in all patients in the operating room and maintained until the day after surgery. All penises were carefully dressed until the removal of the catheter. Urinary retention affected only 13 cases, treated by re-catheterization for 1-2 days. One patient retained the catheter for 10 days. The skin incision was infrapubic in 76 , subcoronal in 24 , subcoronal and penoscrotal in 12 and penoscrotal in 388 patients.

In 122 patients we found a thick cavernous fibrosis and used the Carrion-Rossello cavernotome (13) to dilate the cavernous body to the desired caliber. In 48 cases of penile curvature, insertion of the rods successfully

\section{Table 1.}

Conclusive diagnosis of the 500 patients with penile prostheses.

\begin{tabular}{|lcc|}
\hline & \multicolumn{2}{c|}{ No. patients (\%) } \\
\hline Disease & \multicolumn{2}{c|}{$\mathbf{5 0 0}$} \\
\hline Arterial disease & 192 & $(38.4 \%)$ \\
Venous disease & 137 & $(27.4 \%)$ \\
Peyronie's disease & 70 & $(14 \%)$ \\
Diabetes & 60 & $(12 \%)$ \\
Post pelvic surgery & 30 & $(6 \%)$ \\
Other & 11 & $(2.2 \%)$ \\
\hline
\end{tabular}


straightened the penis. In a few cases a Wilson maneuver (14) was used, with satisfactory results. In 8 patients with a persisting significant curvature after malleable implant, we performed a plaque incision without any suture. In 35 cases (both with malleable and hydraulic implants) we excised the plaque and used various artificial heterologous patches (SIS, Pelvicol, Veritas, Hydrix) (15). There were no significant complications associated with patch insertion.

In the last 10 years, after implanting a hydraulic system we have used aspirating drainage in the scrotum until 1 day post-surgery (16).

All patients underwent a clinical visit 7-15 days after surgery. All patients returned after 30-40 days for a second medical visit. Most also returned regularly after 1 year but 86 (17\%) were lost to follow-up after 1 year.

\section{Prosthesis implantation}

Overall, we implanted 182 silicone semi-rigid rods (74 Almed Implantal, 34 SSDA-GIS, 30 Eurogest, 25 SmallCarrion and 19 Subrini) and 180 malleable rods (66 Mentor Acuform-Coloplast Genesis, 54 AMS 600, 25 JonasJacobi, 14 Vedise, 14 Dacomed Omniphase, 6 Dacomed Duraphase, 1 AMS Spectra). A total of 138 patients with sufficient income or supported by private medical insurance opted for a hydraulic prosthesis. We implanted 18 hydraulic monocomponent prostheses (10 AMS Hydroflex, 8 AMS Dynaflex) and 120 multicomponent prostheses (38 Mentor Alpha I, 25 AMS 700 CX, 20
Coloplast Titan, 17 Mentor Mark II, 14 AMS 700 Ultrex, 3 AMS 700 LGX, 3 AMS Ambicor) (Table 2).

\section{Complications}

Medical complications

We recorded 22 medical complications clearly related to the surgical procedure.

In two cases $(0.4 \%)$ we perforated the septum during cavernous dilation and inserted the two rods in the same cavernous space. After discovering the problem we reinserted the two rods correctly in the cavernous spaces, with good results and no further complications.

In one case $(0.2 \%)$ the tip of the cavernous body was perforated. We detached the glans, applied a patch of Veritas, and re-implanted a rod $0.5 \mathrm{~cm}$ shorter than the length measured during operation. No subsequent complication was recorded.

In another patient $(0.2 \%)$ we perforated the crus of one cavernous body during dilation with the cavernotomes. We performed a new perineal incision to detect the perforation site, which was sutured after placing an RT extender in the crus of the cavernous body (17). The insertion of the rod was subsequently successful.

We did not register any bladder lesion when hydraulic prostheses were implanted.

\section{Hemorrhage}

In $2(0.4 \%)$ cases of semi-rigid prostheses (penoscrotal incision) we recorded a scrotal hematoma the day after

Table 2.

500 penile prostheses implanted in relation with age of patients, mechanical failures, surgical complications and explanted cases with CKF on dialysis.

\begin{tabular}{|c|c|c|c|c|c|c|}
\hline \multicolumn{7}{|c|}{ Age } \\
\hline Prostheses & $\begin{array}{l}\text { Patients } \\
500\end{array}$ & $\begin{array}{l}\text { Yrs, range } \\
20-86\end{array}$ & $\begin{array}{c}\text { Mean } \\
51.0\end{array}$ & $\begin{array}{l}\text { Mechanical } \\
48(9.6 \%)\end{array}$ & $\begin{array}{l}\text { Surgical failures } \\
26(5.2 \%)\end{array}$ & $\begin{array}{c}\text { Explants complications } \\
53(10.6 \%)\end{array}$ \\
\hline Soft Silicone & 182 & $20-73$ & 39.7 & $2(1.2 \%)$ & $7(3.8 \%)$ & $1(0.6 \%)$ \\
\hline Almed Implantal & 74 & $20-73$ & 36.3 & 1 & 3 & 0 \\
\hline Ssda-Gis & 34 & $22-62$ & 43.3 & 1 & 1 & 0 \\
\hline Eurogest & 30 & $29-65$ & 40.2 & 0 & 1 & 1 \\
\hline Small-Carrion & 25 & $27-73$ & 46.2 & 0 & 2 & 0 \\
\hline Subrini & 19 & $30-38$ & & 0 & 0 & 0 \\
\hline Semirigid Malleable & 180 & $28-86$ & 53.7 & $7(3.8 \%)$ & $4(2.2 \%)$ & $8(4.4 \%)$ \\
\hline Mentor Acuform-Coloplast Genesis & 66 & $28-83$ & 53.2 & 0 & 1 & 1 \\
\hline Ams 600 & 54 & $28-85$ & 53.5 & 0 & 2 & 0 \\
\hline Jonas & 25 & $35-65$ & 45.4 & 1 & 0 & 1 \\
\hline Vedise & 14 & $55-67$ & 50.6 & 0 & 0 & 0 \\
\hline Omniphase & 14 & $44-72$ & 67.4 & 3 & 1 & 3 \\
\hline Duraphase & 6 & $49-86$ & 63 & 3 & 0 & 2 \\
\hline Ams-Spectra & 1 & 51 & 51 & 0 & 0 & 1 \\
\hline \multicolumn{7}{|l|}{ HYDRAULIC } \\
\hline Monocomponent & 18 & $43-65$ & 52.2 & $14(77.7 \%)$ & 0 & $8(77.7 \%)$ \\
\hline Ams-Hydroflex & 10 & $47-55$ & 50.5 & 8 & 0 & 8 \\
\hline Ams-Dynaflex & 8 & $43-65$ & 54 & 6 & 0 & 6 \\
\hline Multicomponents & 120 & $26-85$ & 58.4 & $25(20.8 \%)$ & $15(12.5 \%)$ & $36(30 \%)$ \\
\hline Mentor Alpha li & 38 & $27-66$ & 49.6 & 5 & 4 & 9 \\
\hline Ams $700 \mathrm{Cx}$ & 25 & $43-73$ & 65.3 & 7 & 4 & 11 \\
\hline Coloplast Titan & 20 & $26-74$ & 45.4 & 4 & 3 & 6 \\
\hline Mentor Mark li & 17 & $31-65$ & 54.3 & 1 & 0 & 1 \\
\hline Ams700 Ultrex & 14 & $41-85$ & 62.8 & 8 & 3 & 9 \\
\hline Ams700 Lgx & 3 & $66-71$ & 63.3 & 0 & 0 & 0 \\
\hline Ams Ambicor & 3 & $66-70$ & 68 & 0 & 1 & 0 \\
\hline
\end{tabular}


surgery, which required 2 more days of hospitalization and medical treatment.

In the first group of 50 hydraulic prostheses, implanted without any drainage, 11 cases $(22 \%)$ of scrotal hematomas were recorded the day after surgery, requiring longer observation and in 8 cases needle aspiration and medical treatment. Since 2004 we routinely applied scrotal drainage (16) observing only 5 cases $(5.6 \%)$ of scrotal hematoma due to obstruction of the drain. These hematomas were easily evacuated using the tubing of the draining system, prolonging hospitalization (to 3 and 4 days) in just two cases (2/5).

In one of these patients, who underwent AMS 700 CX implantation after excision of a fibrous plaque of IPP and Veritas patch $(3 \times 2 \mathrm{~cm})$ insertion, we recorded an extensive hematoma including the scrotum and penis. This scrotal hematoma begun to appear soon after the deflation of corporal cylinders the day after surgery, even with an empty aspirating drainage. In this case we discovered the hemorrhage after 3-4 hours. We re-inflated the cylinders and after repeated aspiration succeeded in stopping the hemorrhage. This patient developed an infection some weeks later and after 2 months we decided to remove the hydraulic system.

\section{Micturition}

Only 13 of 500 patients $(0.26 \%)$ were unable to urinate after removal of the urethral catheter the day after surgery, thus requiring re-catheterization; this was maintained for the next day in 12 cases, while one patient was discharged with the catheter still fitted. It was removed, after medical treatment, 10 days post-surgery.

\section{Infection}

Fifteen (3\%) cases of infections were recorded. Overall, in 6 patients (1.2\%) we had to explant the prosthesis (19) (Table 2).

In 4 cases we observed high fever, chills and signs of infections in the immediate period after surgery. In 3 cases, intravenous medical therapy resolved the infection. In one case the infection lasted more than 20 days and we decided to explant the prosthesis.

In 2 cases $(0.5 \%)$ of semi-rigid prosthesis and in 5 cases (3.6\%) of hydraulic prosthesis we recorded a prosthesis infection after 3 to 18 months, requiring removal of the prosthesis. Two patients (53 and 62 years, who suffered from diabetes and hypertension) implanted respectively with Mentor Mark II and AMS 700 CX started to develop scrotal swelling with pain and skin perforation due to extrusion of the scrotal pump after 45 days in the first case and 36 days in the second. In both cases we removed the prosthetic system entirely, leading to the disappearance of infectious signs and symptoms. Both patients refused a subsequent penile implant (20).

One patient (62 years, a smoker and hypertensive) started to develop fever and pain at the base of the penis 15 days post-surgery, and a small discharge of purulent yellowish material began to appear from a small hole in the skin at the base of the penis. The amount of purulent material increased on squeezing the penis and inflating the cavernous cylinders. The fistula was repeatedly cleaned with iodopovidone and physiological solution mixed with Gentamicin 3 times a day for 10 days, with resolution of the discharge and ultimate closure of the hole. After 8 years the patient continues to use his prosthesis satisfactorily.

Another "uncommon" infection arose in a 51-year-old patient after replacement of a Mentor Alpha I due to tubing leakage near the reservoir. After implantation of a new Alpha I, the patient started to develop swelling of the left hemiscrotum, with pain when touching the pump. Fever was mild. The patient did not benefit from a complex antibiotic therapy. The presence and persistence of the inflammation and pain referred to the hemiscrotum along with high white blood cells (WBC) counts induced us to remove the hydraulic system after 20 days of complex intravenous therapy, with an immediate drop in fever and WBC counts and resumption of healing. The patient did not wish to remain without a prosthesis. After 7 days without fever we therefore implanted two AMS Spectra rods in order to keep the cavernous bodies open until it was possible to implant another hydraulic system (AMS 700CX), which was fitted in a different hospital 5 months later.

\section{Mechanical problems}

Apical extrusion of one prosthetic rod occurred in just 8 out of 362 semi-rigid (2.2\%) prostheses. In 3 cases we covered the apical rupture and re-implanted a shorter semirigid rod. In 5 cases the patients preferred to retain only one rod, with satisfactory penetrative function (Table 2). Three patients $(0.8 \%)$ with semi-rigid rods complained of the "rotation" of the rods during sexual activity, with some unpleasant discomfort.

We sometimes observed irregularity in the length of the two cavernous bodies at the end of operation, in which case we re-opened the cavernous body and extracted the shorter rod in order to insert a longer Rear Tip extender until obtaining good penile symmetry.

In 2 cases (1.4\%) we had to re-operate due to incorrect positioning and difficult activation of the pump into the scrotum. Scrotal incision and re-positioning of the pump were performed 5 and 25 days after the original operation and were uneventful. The prostheses continue to work after 9 and 11 years.

We explanted 3 OmniPhase (1, 1 and 2 years after implantation) and 2 DuraPhase (1 and 3 years after implantation) prostheses due to breakage. Another patient decided to maintain the broken rods without changing them.

We removed $14(77.7 \%)$ of the 18 self-contained hydraulic prostheses (8 Hydroflex and 6 Dynaflex) due to clearly evident malfunction 4-16 months post-surgery. The other 4 patients with self-contained prostheses were lost to followup; they lived in different cities or in any case far from our private clinic and in the event of any complications, probably consulted a different medical facility.

Leakage of the tubing with a completely non-functional system occurred in 22 cases (15.9\%) from 3 months to 96 months after implantation. Seventeen patients were re-operated shortly thereafter (1-3 months), with implantation of a new hydraulic prosthesis. Two of 5 patients who had discovered the malfunction after several months opted for fitting of a malleable prosthesis. Three patients refused a new implant. 
In 3 cases of AMS700 Ultrex implantation there was a malfunction due to aneurismatic dilatation of the cavernous cylinders appearing 9, 10 and 16 months after the implant. All 3 cases underwent explantation and subsequent successful hydraulic prosthetic re-implantation. In total we explanted $42 / 500$ (8.4\%) prostheses, of which 6/362 (1.6\%) malleable, 14/18 (77.7\%) hydraulic monocomponent and 22/120 (18.3\%) hydraulic multicomponent.

\section{Repeated prostheses}

Three patients received 3 prostheses in the space of 5 years. All of them were first implanted with a Mentor Acuform. After 3 years they wanted to switch to a hydraulic multicomponent prosthesis. They received a Mentor Alpha I (2 cases) and a AMS 700 cx (1 case). Two patients suffered from subsequent infections and 1 from tubing rupture, causing removal of the hydraulic system in all cases. Finally, they were implanted with a semirigid (Almed) prosthesis.

\section{Dissatisfaction, refusal}

Thirty-two patients reported dissatisfaction with the length of the operated penis (22).

In 8 cases, the patients' disappointment was due to perception of the tubing at the base of the penis.

Three patients reported absolute refusal with the prostheses. In 2 cases (one malleable and one hydraulic) patients required subsequent explant (2 and 4 months post-implant).

\section{Conclusions}

In our experience prosthetic implants appear to be a good solution for erectile and penetrative dysfunction. The surgical technique is relatively simple, even if some problems can occur. Our data confirm that this kind of surgery can be performed even in a small private clinic. The possibility of having a penile prostheses under the National Health System continues to be very difficult in Italy. In several public hospitals, even with advanced urological departments, there are no surgeons experienced in penile prosthetic surgery and this solution is not offered to patients with ED. Furthermore, many General Practitioners do not consider a penile prosthesis as a possible mean of restoring penetrative function. For this reason, they do not normally suggest this solution to any patients consulting them during the early phase of the ED diagnostic process. The financial aspect of the surgical treatment of ED may greatly limit the patient's choice if no other medical treatments are effective (23). The number of patients submitted to PPI appears in line with other distinguished European urological centers $(24,25)$.

In our experience, younger patients preferred semi-rigid silicone prostheses, considering them simpler to use during sexual intercourse. Many of our younger patients reported a subsidiary spontaneous erection of the tissue surrounding the prosthetic rods during the preliminary sexual phase (26). This "accessory" erection is also considered highly positive from an emotional point of view. Many patients sometimes used 5PDEi to achieve better subsidiary tumescence. The 6 patients aged over 80 years did not experience any complications or problems different to those in younger patients (27). They all confirmed their satisfaction at the 1 -year follow-up visit. In 1 case with Coloplast Titan inflatable prosthesis a TURP for BPH was easily performed.

Patient satisfaction with hydraulic prostheses was very high (80\%). The most important aspect is related to the fact of having an erection only when sexual intercourse is desired. Another reason is the possibility of having sexual intercourse without informing their partner of its presence, which can be easily masked.

Many of our patients reported that they did not tell their partners about their prosthesis, even though we consider the partner's cooperation to be very important, especially in the first sexual experiences following the penile implant. Almost all our patients reported some relational problems during the first months after PPI. It is extremely important not to have to conceal the presence of the prosthesis and to practice pumping and deflating the cylinders. In our experience a well-trained male can hide his prosthesis from a new partner for a considerable period.

More than $80 \%$ of partners who had been told about the prosthesis declared their satisfaction with their partner's choice and no sexual refusal was reported to us.

\section{REFERENCES}

1. Wesson MB. The value of testosterone to men past middle age. J Am Geriatr Soc. 1964; 12:1149.

2. Margolis R, Leslie $\mathrm{CH}$. Review of studies on a mixture of nux vomica, yohimbine and methyl testosterone in the treatment of impotence. Curr Ther Res Clin Exp. 1966; 8:280.

3. Small MP, Carrion HM, Gordon JA. Small-Carrion penile prosthesis: new implant for management of impotence. Urology. 1975; 5:479.

4. Scott FB, Bradley WE, Timm GW. Management of erectile impotence: use of inflatable prostheses. Urology. 1973; 2:80.

5. Lewis RW. Arteriovenous surgeries: do they make any sense? In: Lue TF. World Book of Impotence.London: Smith-Gordon; 1992; p.199.

6. Craig F, Donatucci MD, Lue TF. Venous surgery: are we kidding ourselves? In: Lue TF World Book of Impotence. London: SmithGordon; 1992; p. 221.

7. Virag R. Intracavernous injection of papaverine for erectile failure. Lancet. 1982; 2:938.

8. Ishii $\mathrm{N}$, Watanabe $\mathrm{H}$, Irisawa $\mathrm{C}$, et al. Intracavernous injection of prostaglandin E1 for treatment of erectile impotence. J Urol. 1989; 141:323.

9. Nadig PW, Ware JC, Blumoff R. Non invasive device to produce and maintain an erection-like state. Urology. 1986; 27:12.

10. Padma-Nathan H, Keller T, Poppiti R, et al. Hemodynamic effects of intraurethral alprostadil: the Medicated Urethral System for Erection(MUSE). J Urol. 1994; 151:469.

11. Boolell M, Allen MJ, Ballard SA, et al. Sildenafil an orally active type 5 cyclic GMP-specific phosphodiesterase inhibitor for the treatment of penile erectile dysfunction. Int J Impot Res. 1996; 8:47.

12. Yeung LL, Grewal S, Bullock A, et al. A comparison of chlorhexidine-alcohol versus povidone-iodine for eliminating skin flora before 
genitourinary prosthetic surgery: a randomized controlled trial. J Urol. 2013; 189:136.

13. Pozza D, Rossello Barbarà M, Carrion H. Lutilizzazione del Cavernotomo di Carrion-Rossello per l'impianto di protesi intracavernose. Acta Urol Ital. 1993; 2:87.

14. Wilson SK, Delk JR 2nd. A new treatment for Peyronie's disease: modeling the penis over an inflatable penile prosthesis. J Urol. 1994; 152:1121

15. Egydio PH, Kuehhas FE. Distal penile shaft reconstruction and reinforcement: the "double-windsocks" technique. J Sex Med. 2013; 10:2571.

16. Sadeghi-Nejad H, Ilbeigi P, Wilson SK, et al. Multi-institutional outcome study on the efficacy of closed-suction drainage of the scrotum in three-piece inflatable penile prosthesis surgery. Int J Impot Res. 2005; 17:535.

17. Wilson SK. Rear tip extender sling: a quick and easy repair for crural perforation. J Sex Med. 2007; 4:231.

18. Garber BB, Bickell M. Delayed postoperative hematoma formation after inflatable penile prosthesis implantation. J Sex Med. 2014; 28:1111.

19. Muench PJ. Infections versus penile implants: the war on bugs. J Urol. 2013; 189:1631.

20. Talib RA, Shamsodini A, Salem EA, et al. Isolated pump erosion of an inflatable penile prosthesis through the scrotum in a diabetic patient. Arch Ital Urol Androl. 2013; 85:53.

21. Montague DK. Penile prosthesis implantation: size matters. Eur Urol. 2007; 51:887.

22. Caraceni E, Utizi L. A questionnaire for the evaluation of quality of life after after penile prosthesis implant: quality of life and sexuality with penile prosthesis ( $O L L S P P)$ : to what extent does the implant affect the patient's life? J Sex Med. 2014; 11:1005.

23. Mondaini N, Sarti E, Giubilei G, et al. Penile prosthesis surgery in out-patient setting: Effectiveness and costs in the "spending review" era. Arch Ital Urol Androl. 2014; 86:161.

24. Minervini A, Ralph DJ, Pryor JP. Outcome of penile prosthesis implantation for treating erectile dysfunction: experience with 504 procedures. BJU Int. 2006; 97:129.

25. Natali A, Olianas R, Fisch M. Penile implantation in Europe: successes and complications with 253 implants in Italy and Germany. J Sex Med. 2008; 5:1503.

26. Grasso M, Lania C, Fortuna F, et al. Evaluation of post-operative residual function of corpora cavernosa after softpenile prosthesis implant for Peyronie's disease. Arch Ital Urol Androl. 2006; 78:49.

27. Morey AF. Re: should being aged over 70 years hinder penile prosthesis implantation? J Urol. 2011; 185:1328.

\section{Correspondence}

Diego Pozza, MD (Corresponding Author)

diegpo@tin.it

Mariangela Pozza, MD

mariangelapozza@gmail.com

Marco Musy, MD

tortas@libero.it

Studio di Andrologia e di Chirurgia Andrologica

Via B.Gozzoli 82, 00142 Roma, Italy

Carlotta Pozza, MD

carlotta.pozza@gmail.com

Department of Experimental Medicine, Sapienza University of Rome, Roma, Italy 